\title{
The daily variations of the vertical $(Z)$ element of the geomagnetic field around the coast of mainland Australia
}

\author{
R. J. Stening and T. Reztsova \\ School of Physics, University of New South Wales, Sydney 2052, Australia \\ (Received May 19, 2006; Revised January 22, 2007; Accepted February 27, 2007; Online published June 27, 2007)
}

\begin{abstract}
Use is made of an array of magnetic stations spread across the Australian mainland to examine the daily variation of the vertical element $Z$ of the magnetic field. On sections of the west and east coasts visual inspection of $\mathrm{Z}$ variations shows that they respond mainly to the onshore component of the horizontal field as predicted by Bennett and Lilley, though only south of about $22^{\circ} \mathrm{S}$ on the east coast and south of $20^{\circ} \mathrm{S}$ on the west coast. On the north and south coasts this "coast effect" is not clearly seen at periods corresponding to the daily variation, though it sometimes appears on shorter time scales. On the north and south coasts $\mathrm{Z}$ appears to be mainly controlled by the decrease with latitude of the overhead eastward ionospheric currents as measured by the latitude gradient in the northward field, $X$. By subtracting the vector $Z$ variation at an inland station from $Z$ at a coastal station, the anomalous coastal effect in $\mathrm{Z}$ is calculated at periods of 12 and $24 \mathrm{~h}$. These data show that the coastal effect is not just related to the horizontal onshore component but that some phase change is also required. An increase with latitude of the overhead eastward currents is sometimes found in morning hours corresponding to the morning current system identified in earlier work.
\end{abstract}

Key words: Sq variations, coastal effect, induction, ionospheric currents.

\section{Introduction}

The daily variations of the magnetic field observed on days free of magnetic disturbance or storms are thought to be due to a system of electric currents flowing in the ionosphere, commonly known as the Sq system (Matsushita, 1967). Those who study this system usually use the horizontal northward $(\mathrm{X})$ and eastward $(\mathrm{Y})$ elements of the variations of the field but avoid the use of the vertical $(Z)$ field as it is often influenced by other effects. The $\mathrm{Z}$ field is most affected by different induced currents caused by conductivity anomalies within the earth and by the proximity of a coastline.

Broadly speaking, the $\mathrm{Z}$ variation during times of magnetic quiet has a peak around local noon in the southern hemisphere. This can be seen in the diagrams of Matsushita (1967) and arises mainly from the decrease with increasing latitude of the eastward currents in the ionosphere, including their reversal to westward beyond the focus of the Sq current system.

From August 1989 to June 1990 an array of 54 magnetometers was running spread across the Australian mainland. This project was called the Australia-Wide Array of Geomagnetic Stations (AWAGS). Further information on the array may be found in Chamalaun and Barton (1993a, b). These data provide an unique opportunity to study the $\mathrm{Z}$ variation field in some detail. Please note that the emphasis of the present study is on times when no significant magnetic disturbance is present so that the magnetic variations

Copyright (c) The Society of Geomagnetism and Earth, Planetary and Space Sciences (SGEPSS); The Seismological Society of Japan; The Volcanological Society of Japan; The Geodetic Society of Japan; The Japanese Society for Planetary Sciences; TERRAPUB. seen are mainly due to the Sq current system in the ionosphere and the currents induced in the earth by the magnetic fields produced by that system.

Lilley and Parker (1976) showed that the vertical (Z) variation of the field on a magnetically quiet day $\left(\mathrm{Kp} \leq 1^{-}\right)$ was consistently larger on the west coast compared to the rest of the continent, including the east coast. They further showed that the anomalous $\mathrm{Z}$ field at Gnangara, on the west coast, was best correlated with the onshore component of the eastward field $\mathrm{Y}_{O}$.

Much of the earlier work on the geomagnetic coast effect, both observational and theoretical, has been reviewed by Parkinson and Jones (1979).

Also many of the investigations have concentrated on shorter period magnetic variations. For example Everett and Hyndman (1967) restricted their study to frequencies greater than 4 cycles per day. Gough et al. (1974) concentrated on times during magnetic storms and periods from a half hour to several hours. Srivastava et al. (2001) examined both $\mathrm{Sq}$ ranges and substorm behaviour at Indian stations and found different behaviour of the $\mathrm{Z}$ component of Sq on the east and west coasts. This led them to postulate a region of lower conductivity in the east.

Bennett and Lilley (1973) obtained separate variations of amplitude and phase for 6,8,12 and 24-hour periods for the three magnetic elements over a magnetometer array in south-east Australia. They then identify a "normal" magnetic variation at a magnetic station distant from the coast and vectorially subtract this from the variations at all stations to obtain an anomalous variation, $\mathrm{Z}_{A}$, in the case of the vertical component. They suggest that the best correlation for $\mathrm{Z}_{A}$ again occurs with the onshore component $\mathrm{Y}_{O}$ of the 


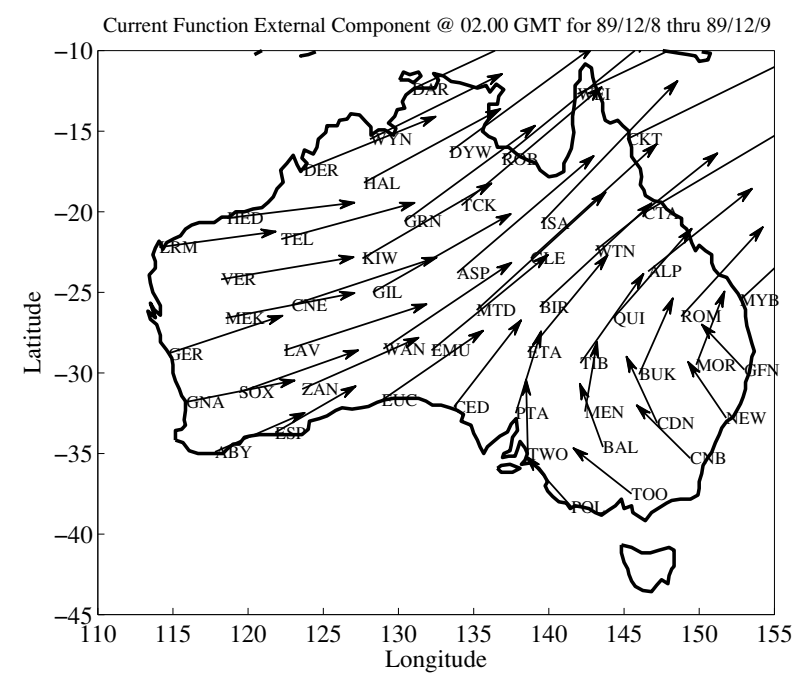

Fig. 1. Map showing the location of observing stations. The vectors correspond to the magnetic field at $2 \mathrm{~h}$ UT on 9 December 1989, rotated clockwise through $90^{\circ}$. A vector length equivalent to $5^{\circ}$ of longitude on the abscissa scale is equivalent to $28.5 \mathrm{nT}$.

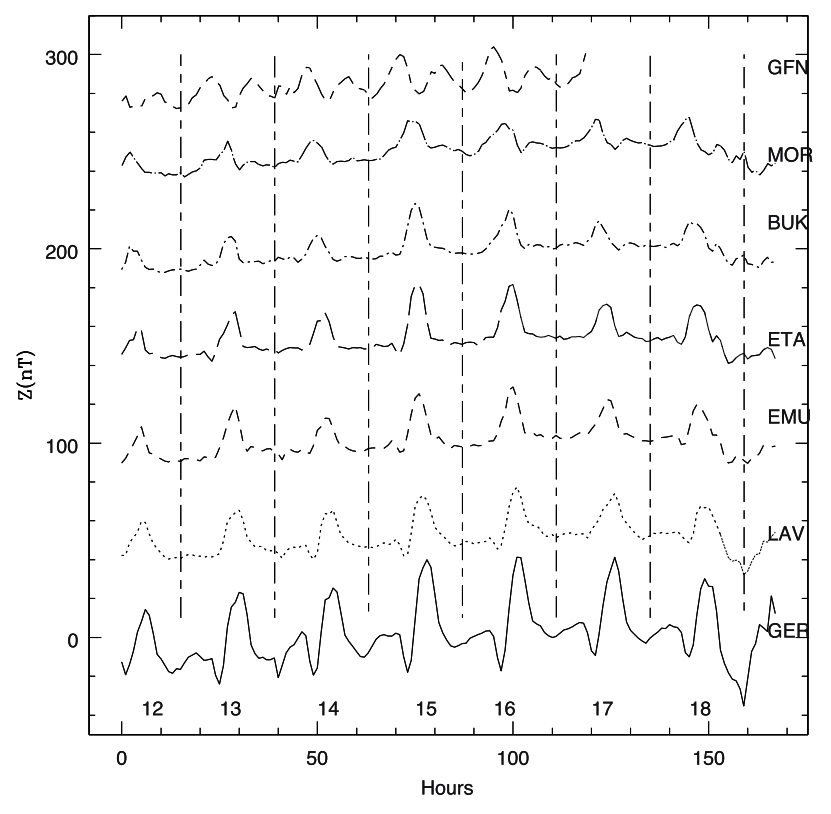

Fig. 2. $\mathrm{Z}$ variations at a chain of stations from the west coast at the bottom (GER) to the east coast at the top (GFN) during a fairly quiet magnetic period from 12 to 18 May 1990.

horizontal field variation. We shall seek to test this correlation with a larger number of stations around the Australian coast. Bennett and Lilley suggest that this effect might be explained by "lateral conductivity contrasts between ocean and land". After examining various possibilities, Parkinson and Jones select the most likely cause of the coast effect as "induction in large vertical loops involving the ocean water, the oceanic lithosphere, and possibly the conductosphere".

Our interest in this research is more focussed on the ionospheric currents and what the $\Delta \mathrm{Z}$ variation can tell us about them. The effects of irregular induction will contaminate the ionospheric effects and so we need to be aware where this happens. During the course of our investigations we found that the "coast effect" on induction was restricted to

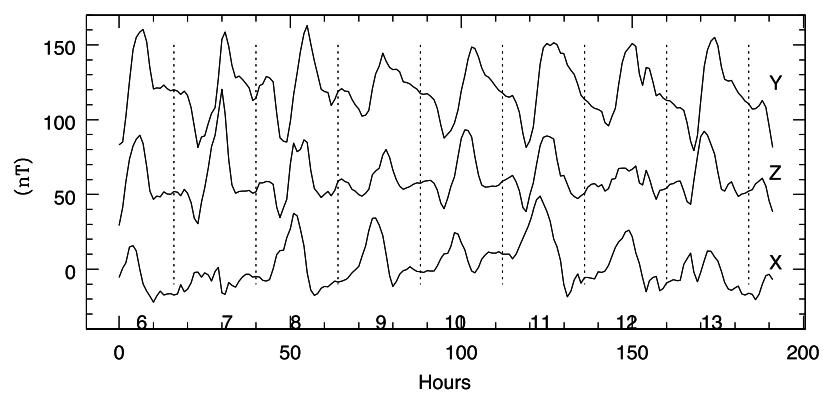

Fig. 3. Hourly mean value variations of the three components of the magnetic field at Learmonth (LRM) during 6 to 13 December 1989. The vertical lines indicate local midnight, at which each curve is approximately at the zero level. The two upper curves are displaced for easier viewing. The days in December are indicated just above the horizontal axis.

certain parts of the Australian coast while elsewhere the primary source of $\Delta \mathrm{Z}$ lay in the change with latitude of the amplitude of the eastwards ionospheric current.

\section{Results}

Figure 1 shows the location of some of the magnetometers used and an indication of the ionospheric current system at 2 h UT on 9 December 1989. This figure also appears in Stening et al. (2005a) and is included here because it clearly shows the effects of the dominant current systems. The arrows actually represent measured magnetic field strengths after the magnetic vector has been rotated clockwise through $90^{\circ}$, giving an indication of equivalent overhead ionospheric current flow. In Fig. 1 we can see the Sq current whorl coming in from the east and meeting up with another eastward current system in the centre of the Australian continent. Local noon is at $150^{\circ} \mathrm{E}$ longitude. All magnetic fields discussed in this paper have had a midnight value subtracted. The midnight value is obtained as an average of the preceding and succeeding midnight values at each station.

In Fig. 2 we plot hourly values of the $\mathrm{Z}$ variation during seven days in May 1990 at locations from the west coast at GER to the east coast at GFN (there are some data missing from GFN). The largest amplitude is on the west coast where the $\mathrm{Z}$ variation seems to follow the local $\mathrm{Y}$ variation. An example Fig. 3 shows this.

If we travel eastward across Fig. 2, the morning minimum gets smaller until it has mostly vanished at EMU. The eastern station at GFN has an afternoon minimum. Again this afternoon minimum gets smaller going westwards away from the coast. Except near the east coast the post-noon maximum (at about $14 \mathrm{~h} \mathrm{LT}$ ) dominates throughout. Figure 2 illustrates how different the east and west coast $\mathrm{Z}$ variations are from one another.

We performed a Fourier analysis on some of the data in Fig. 2, extracting the 24, 12 and 8 hour periods and using the first three days data from 12 to 14 May. Results from the following three days (15-17 May), when available, were similar. The amplitudes and phases are plotted in Fig. 4 as they vary with longitude. The results are similar to those given by Whellams (1996) in contour form but we have used data from a different time (he used the 6-13 

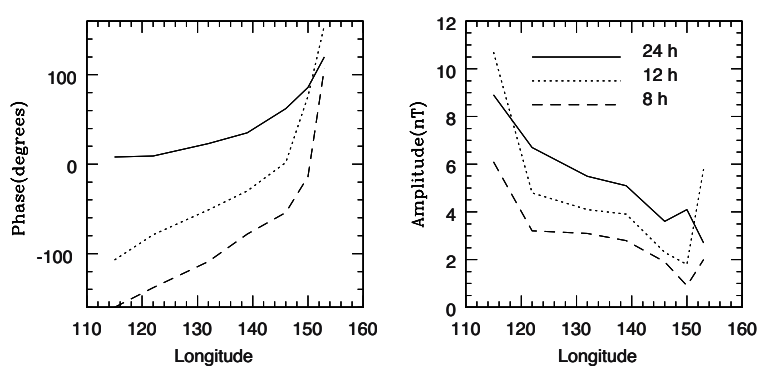

Fig. 4. Variations with longitude of the phase (left panel) and amplitude (right panel) of three Fourier components derived from $\mathrm{Z}$ variation data for 12-14 May 1990 from the stations of Fig. 2.

December 1989 data). Normal expected phase progression would be $1^{\circ}$ of phase for $1^{\circ}$ of longitude for the $24 \mathrm{~h}$ period, $2^{\circ}$ of phase per $1^{\circ}$ of longitude for the $12 \mathrm{~h}$ period and so on. The outstanding features in Fig. 4 are the fairly abrupt increases in amplitude of all harmonics on the west coast, with some increase also on the east coast, and the rapid phase change on the east coast. If the amplitude and phase are considered as a vector and the "normal" inland station vector is subtracted from the coastal station vector, following the method of Bennett and Lilley (1973), it can be seen that an anomalous $\mathrm{Z}$ variation is isolated in both cases, on the west coast on account of the amplitude difference and on the east coast primarily because of the phase difference.

\section{Derivation of "Anomalous" Coastal Z Values}

Following Bennett and Lilley (1973) we have calculated the anomalous vertical component $\mathrm{Z}_{A}$ at coastal stations by performing a vector subtraction of $Z$ at a nearby inland station from the $\mathrm{Z}$ at the coastal station at a particular frequency. Using eight days of hourly data from 6 to $13 \mathrm{De}-$ cember, 1989, we derive the amplitude and phase of the various elements at periods of $24 \mathrm{~h}$ and $12 \mathrm{~h}$ by performing a least squares fit to the data. Initially we also calculated for the $8 \mathrm{~h}$ component but found that the error in the fit often exceeded the amplitude. The results are shown in Table 1 where the stations are arranged in order, travelling clockwise around the coast. The time of maximum $t_{m}$ of each harmonic of period $T$ is related to the phase $\phi$ by $t_{m}=(1 / 4-\phi / 360) T$. The increased coastal amplitude in $\mathrm{Z}$, occurring on the west and north coasts, can be seen from ABY up to DAR with the increase in the $12 \mathrm{~h}$ harmonic being greater than in the $24 \mathrm{~h}$ component. From HED round to DAR the phase of $\mathrm{Z}_{A}$ agrees with that of $\mathrm{Y}$ at the coastal stations to within $30^{\circ}$, except for the $12 \mathrm{~h}$ component at DER where the $Z_{A}$ amplitude is quite small anyway (when the amplitude of $Z_{A}$ is less than about $2.0 \mathrm{nT}$ its statistical significance starts to become suspect).

We might try to understand the result at LRM, where the $\mathrm{Z}_{A}$ phase is $49^{\circ}$ ahead of $\mathrm{Y}_{\text {coastal }}$, by supposing that it is the onshore component $\mathrm{Y}_{O}=\mathrm{Y} \cos \theta+\mathrm{X} \sin \theta$ which relates to $\mathrm{Z}_{A}$ where $\theta$ is the angle between the coastline and North. In this case a value of $\theta=60^{\circ}$, for the $24 \mathrm{~h}$ component, gives a reasonable value for the phase of $Z_{A}$ to agree with that of the onshore component $\mathrm{Y}_{O}$. This is rather difficult to relate to the actual coastline, as LRM (Learmonth) is situated within a gulf at a point where the coastline angle changes direction.

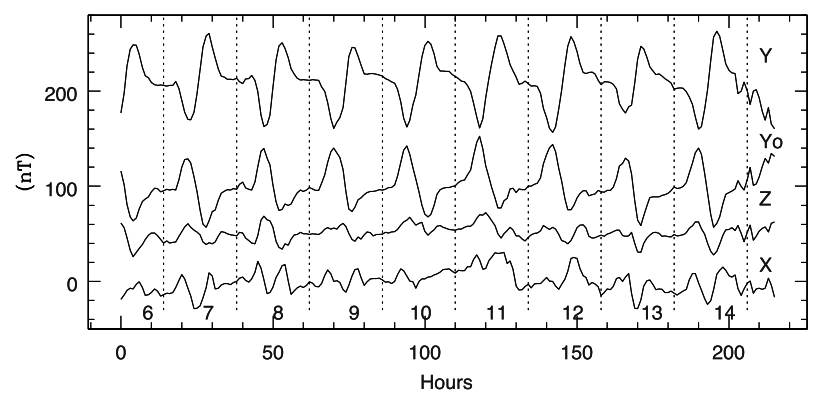

Fig. 5. Newcastle plots for 6-13 December 1989 for X, Y, Z and for the onshore component $\mathrm{Y}_{O}$.

For the $12 \mathrm{~h}$ component there is only a difference of $20^{\circ}$ between $\mathrm{Z}_{A}$ and $\mathrm{Y}$ and so the required value of $\theta$ would be smaller, about $45^{\circ}$. At GER the angle comes to be about $73^{\circ}$ for the $24 \mathrm{~h}$ period and $80^{\circ}$ for $12 \mathrm{~h}$, whereas the actual angle between the coastline and north is more like $30^{\circ}$.

From ESP round to TOO, that is all along the south coast, the amplitudes of $Z_{A}$ are small and of doubtful statistical significance, with the exception of TWO.

From $\mathrm{CNB}$ up to MYB, on the east coast, the phase difference between $\mathrm{Y}_{\text {coast }}$ and $\mathrm{Z}_{A}$ lies between $130^{\circ}$ and $145^{\circ}$, except the $12 \mathrm{~h}$ harmonic at MYB where it is $158^{\circ}$. The latter result is an example where it is impossible to find an angle $\theta$ so that the phase of $\mathrm{Z}_{A}$ can be related to an onshore component, because the amplitude of $\mathrm{X}_{\text {coast }}$ is very small and not significantly different from zero. It follows that any difference between the phases of $Z_{A}$ and $Y_{\text {coast }}$ must have other physical influences present and the method used above to derive a "theoretical $\theta$ " from the data in Table 1 cannot be considered reliable. The phase relation between $\mathrm{Z}$ and the onshore component of $\mathrm{Y}, \mathrm{Y}_{O}$, can be seen in the raw data plotted in Fig. 5 where $Z$ at Newcastle is roughly in antiphase to $\mathrm{Y}$ at Newcastle and in phase with $\mathrm{Y}_{O}$. Here we estimate the coastline at Newcastle to run at $21.5^{\circ}$ east of north so the onshore component will be $\left(\mathrm{X} \sin 21.5^{\circ}-\mathrm{Y} \cos \right.$ $\left.21.5^{\circ}\right)$.

At ROB, CTA and CKT (12 h harmonic), $\mathrm{Z}_{A}$ is insignificant. WEI is an exception in this region. It might be argued that CTA is quite far from the coast (about $110 \mathrm{~km}$ ) but a lunar ocean effect was detected there (Stening and Hopgood, 1991).

To confirm these results we also calculated the same information for another time period, 12-18 May. As May is more towards the winter season, amplitudes are generally smaller; fewer are large enough to be considered statistically significant. We note here some comparisons. For the GFN/MOR pair, $Z_{A}$ is again significant $(6.4 \mathrm{nT}$ for the $12 \mathrm{~h}$ harmonic) and the phase difference between $Z_{A}$ and $Y_{\text {coast }}$ is $128^{\circ}$, very similar to that in December. For the ABY/SOX pair and the $12 \mathrm{~h}$ harmonic, the $\mathrm{Z}_{A}$ and $\mathrm{Y}_{\text {coast }}$ phases agree to within $3^{\circ}$. The CNB/BAL pair also exhibit a similar relationship in May as in December.

Finally we performed a few analyses using a larger data set of 15 days in January 1990, but where Kp reached $3^{+}$ at times, and again found very similar results for $\mathrm{Y}$ and $\mathrm{Z}$ phases at GFN/MOR and NEW/CDN. 
Table 1. Amplitudes and phases of 12 and 24 hour components at various stations (6-13 December 1989).

\begin{tabular}{|c|c|c|c|c|c|c|c|c|c|c|c|c|}
\hline Coast. st. & Inland st. & Period (hrs) & $\mathrm{Z}_{i}$ ampl & $\mathrm{Z}_{i}$ phase & $\mathrm{Z}_{c}$ ampl & $\mathrm{Z}_{c}$ phase & $\mathrm{Z}_{a}$ ampl & $\mathrm{Z}_{a}$ phase & $\mathrm{Y}_{\text {coast }} \mathrm{ampl}$ & $Y_{\text {coast }}$ phase & $\mathrm{X}_{\text {coast }}$ ampl & $\mathrm{X}_{\text {coast }}$ phase \\
\hline WEI & ISA & 24 & 5.7 & 38.6 & 9.5 & 15.3 & 4.8 & 347.1 & 16.4 & 323.2 & 19.3 & 67.9 \\
\hline WEI & ISA & 12 & 3.4 & 359.0 & 6.2 & 342.8 & 3.1 & 325.5 & 13.9 & 292.4 & 6.5 & 30.3 \\
\hline CKT & ISA & 24 & 5.7 & 38.6 & 7.0 & 19.1 & 2.5 & 329.6 & 18.0 & 325.3 & 18.5 & 73.2 \\
\hline CKT & ISA & 12 & 3.4 & 359.0 & 4.0 & 358.0 & 0.7 & 353.0 & 15.7 & 297.9 & 5.9 & 48.4 \\
\hline CTA & WTN & 24 & 6.8 & 40.9 & 6.4 & 37.3 & 0.5 & 272.1 & 20.1 & 328.9 & 14.3 & 79.1 \\
\hline CTA & WTN & 12 & 5.2 & 9.5 & 4.7 & 14.6 & 0.8 & 160.4 & 17.4 & 302.7 & 3.9 & 68.6 \\
\hline MYB & ROM & 24 & 5.4 & 59.8 & 3.3 & 116.4 & 4.5 & 201.9 & 23.8 & 332.8 & 10.0 & 82.7 \\
\hline MYB & ROM & 12 & 4.5 & 52.2 & 5.9 & 107.4 & 5.0 & 155.5 & 20.0 & 313.5 & 1.0 & 141.3 \\
\hline GFN & MOR & 24 & 5.1 & 70.6 & 4.5 & 138.3 & 5.4 & 199.9 & 24.7 & 334.7 & 5.1 & 86.7 \\
\hline GFN & MOR & 12 & 4.1 & 68.3 & 5.4 & 140.1 & 5.7 & 183.6 & 20.7 & 315.7 & 3.7 & 226.8 \\
\hline NEW & $\mathrm{CDN}$ & 24 & 5.8 & 62.5 & 4.3 & 136.5 & 6.1 & 200.6 & 24.3 & 334.6 & 2.0 & 58.3 \\
\hline NEW & $\mathrm{CDN}$ & 12 & 3.4 & 35.8 & 4.9 & 142.3 & 6.7 & 171.4 & 19.9 & 315.0 & 5.9 & 241.5 \\
\hline CNB & BAL & 24 & 7.2 & 52.9 & 4.2 & 94.9 & 5.0 & 198.7 & 25.6 & 336.2 & 0.4 & 182.0 \\
\hline CNB & BAL & 12 & 4.2 & 12.7 & 1.7 & 109.5 & 4.7 & 172.4 & 20.8 & 314.0 & 6.9 & 230.0 \\
\hline TOO & BAL & 24 & 7.2 & 52.9 & 5.9 & 57.0 & 1.4 & 215.9 & 26.4 & 336.0 & 2.9 & 292.1 \\
\hline TOO & BAL & 12 & 4.2 & 12.7 & 2.4 & 11.7 & 1.8 & 194.0 & 20.5 & 311.9 & 8.2 & 227.9 \\
\hline POL & BAL & 24 & 7.2 & 52.9 & 7.4 & 44.2 & 1.1 & 328.2 & 23.3 & 330.7 & 4.9 & 310.1 \\
\hline POL & BAL & 12 & 4.2 & 12.7 & 3.8 & 348.2 & 1.7 & 256.7 & 18.2 & 307.8 & 7.1 & 239.4 \\
\hline TWO & MEN & 24 & 7.3 & 53.9 & 10.0 & 41.4 & 3.3 & 12.8 & 23.6 & 325.4 & 2.0 & 31.4 \\
\hline TWO & MEN & 12 & 4.4 & 18.1 & 6.7 & 355.6 & 3.2 & 323.6 & 18.5 & 297.6 & 4.6 & 230.6 \\
\hline PTA & ETA & 24 & 8.3 & 47.5 & 7.9 & 49.1 & 0.5 & 198.9 & 22.8 & 324.8 & 4.3 & 50.6 \\
\hline PTA & ETA & 12 & 5.4 & 10.7 & 3.8 & 355.3 & 2.0 & 221.7 & 18.3 & 300.0 & 3.4 & 240.3 \\
\hline CED & EMU & 24 & 7.3 & 43.2 & 8.8 & 40.9 & 1.5 & 29.3 & 21.4 & 318.5 & 6.0 & 60.9 \\
\hline CED & EMU & 12 & 4.3 & 357.0 & 5.3 & 347.7 & 1.3 & 316.3 & 16.9 & 288.9 & 2.4 & 248.4 \\
\hline EUC & WAN & 24 & 7.4 & 31.6 & 8.4 & 38.0 & 1.3 & 76.8 & 20.4 & 315.8 & 7.3 & 54.5 \\
\hline EUC & WAN & 12 & 4.9 & 343.9 & 5.5 & 335.3 & 1.2 & 299.8 & 15.5 & 286.3 & 1.9 & 287.3 \\
\hline ESP & SOX & 24 & 10.6 & 26.3 & 10.6 & 27.0 & 0.1 & 111.9 & 19.5 & 311.3 & 5.0 & 68.8 \\
\hline ESP & SOX & 12 & 8.3 & 318.7 & 8.4 & 325.1 & 0.9 & 49.5 & 14.2 & 276.2 & 0.4 & 252.3 \\
\hline $\mathrm{ABY}$ & SOX & 24 & 10.6 & 26.3 & 17.1 & 27.3 & 6.5 & 28.7 & 19.3 & 305.9 & 3.8 & 57.7 \\
\hline $\mathrm{ABY}$ & SOX & 12 & 8.3 & 318.7 & 15.2 & 325.2 & 7.0 & 332.9 & 13.0 & 267.0 & 1.3 & 256.0 \\
\hline GNA* & SOX & 24 & 9.7 & 22.9 & 13.4 & 25.2 & 3.7 & 31.4 & 16.4 & 304.0 & 6.6 & 90.2 \\
\hline GNA* & SOX & 12 & 8.0 & 311.8 & 12.7 & 318.1 & 4.8 & 328.6 & 13.8 & 265.9 & 3.9 & 360.0 \\
\hline GER & LAV & 24 & 7.4 & 22.6 & 14.5 & 21.7 & 7.2 & 20.7 & 19.1 & 306.2 & 9.9 & 54.3 \\
\hline GER & LAV & 12 & 4.9 & 315.1 & 13.2 & 316.0 & 8.3 & 316.5 & 12.3 & 263.4 & 3.9 & 339.4 \\
\hline LRM & VER & 24 & 7.5 & 5.3 & 12.8 & 6.1 & 5.3 & 7.3 & 20.0 & 318.4 & 13.3 & 54.6 \\
\hline LRM & VER & 12 & 6.2 & 300.1 & 12.0 & 292.5 & 6.0 & 284.6 & 13.3 & 264.6 & 6.0 & 358.7 \\
\hline HED & TEL & 24 & 4.8 & 354.1 & 7.6 & 345.1 & 3.0 & 330.4 & 16.6 & 307.4 & 15.8 & 53.2 \\
\hline HED & TEL & 12 & 4.2 & 295.0 & 7.4 & 285.3 & 3.3 & 272.9 & 11.0 & 262.4 & 6.8 & 353.1 \\
\hline DER & HAL & 24 & 4.4 & 31.2 & 5.2 & 16.6 & 1.5 & 328.1 & 16.3 & 303.2 & 17.3 & 61.0 \\
\hline DER & HAL & 12 & 4.4 & 325.9 & 6.3 & 319.7 & 2.0 & 305.7 & 11.2 & 263.7 & 7.7 & 3.7 \\
\hline WYN & HAL & 24 & 4.4 & 31.2 & 6.7 & 353.0 & 4.3 & 313.2 & 15.9 & 303.5 & 17.9 & 60.2 \\
\hline WYN & HAL & 12 & 4.4 & 325.9 & 5.4 & 303.9 & 2.1 & 252.8 & 11.3 & 264.8 & 6.7 & 10.5 \\
\hline DAR & DYW & 24 & 6.7 & 12.0 & 9.3 & 354.6 & 3.5 & 319.7 & 15.8 & 307.0 & 21.3 & 60.0 \\
\hline DAR & DYW & 12 & 5.0 & 322.3 & 6.9 & 304.9 & 2.6 & 269.0 & 11.7 & 270.7 & 9.1 & 12.3 \\
\hline ROB & DYW & 24 & 6.7 & 12.0 & 7.0 & 18.4 & 0.8 & 84.5 & 17.2 & 307.8 & 16.4 & 65.5 \\
\hline ROB & DYW & 12 & 5.0 & 322.3 & 4.8 & 334.5 & 1.1 & 72.9 & 13.2 & 279.6 & 5.3 & 25.3 \\
\hline
\end{tabular}

*6-9 Dec

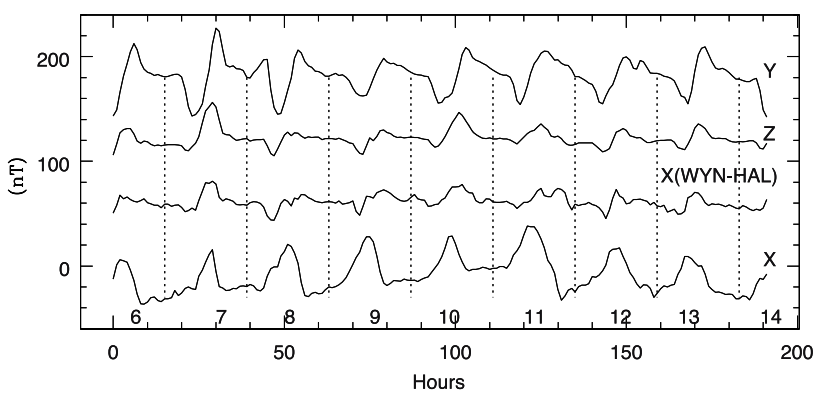

Fig. 6. Wyndham X, Y and Z on 6-13 December, 1989 with Wyndham minus Hall's Creek $X$ to give $\mathrm{dX} / \mathrm{d} \phi$.

\section{Z Variation where There is Little Coast Effect}

At Wyndham (WYN), on the north coast, $\mathrm{Z}$ does not clearly correlate well with either of the other components (Fig. 6). Wyndham is actually at the head of Cambridge
Gulf, about $80 \mathrm{~km}$ south of the main coastline. However Darwin (DAR) and Wyndham have similar variations in $\mathrm{Z}$, as can also be seen in the phases of their harmonics in Table 1. Figure 6 shows how remarkably the $\mathrm{Z}$ variation at WYN changes from day to day. On December 7 and 10 the maxima are larger than the nearby days. These days are different in that the Sq current system focus is at 28$30^{\circ}$ latitude while on the other days the focus is around $40^{\circ}$. It is reasonable to expect, other things being equal, that, when the focus is closer to the equator, the eastward currents would decrease in magnitude more rapidly moving from the equator to the focus than when the focus is further away. Thus a lower latitude focus might result in a larger $\mathrm{Z}$ variation at stations between the focus and the equator. (The focus of the current system is determined by estimating the latitude at which the horizontal magnetic variation $\Delta \mathrm{H}$ goes to zero at the time when the declination variation $\Delta \mathrm{D}$ goes to zero, as shown in Stening et al. (2005b)). 


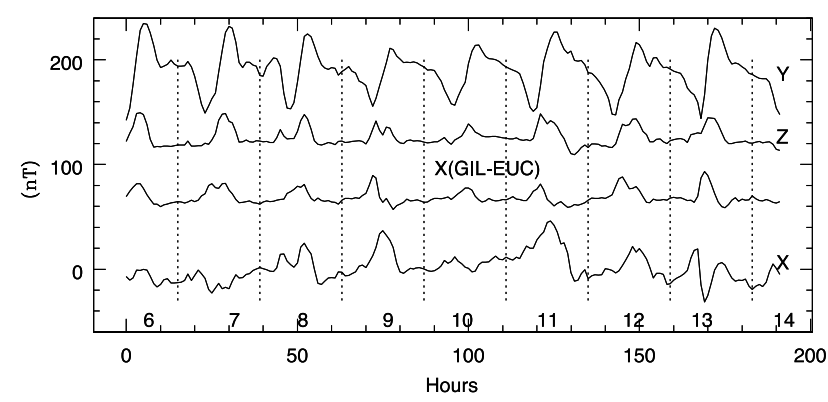

Fig. 7. $\mathrm{X}, \mathrm{Y}$ and $\mathrm{Z}$ variations at Eucla (EUC) together with an estimate of $\mathrm{dX} / \mathrm{d} \phi$ obtained by subtracting $\mathrm{X}$ values at Eucla from those at Giles (GIL), 6-13 December 1989.

If the $\mathrm{Z}$ variation reflects changes in ionospheric current strength with latitude, then we might expect a relation between $\mathrm{Z}$ and the latitude gradient of the $\mathrm{X}$ component $\mathrm{dX} / \mathrm{d} \phi$. Figure 6 shows that the shape, if not the amplitude, of the $\mathrm{Z}$ variation at Wyndham is indeed similar to that of the gradient in $\mathrm{X}$ as estimated by differencing the hourly $\mathrm{X}$ values at Wyndham $\left(15.5^{\circ} \mathrm{S}\right)$ and Halls Creek $\left(18.2^{\circ} \mathrm{S}\right)$.

We were interested to determine where the changeover occurred from $\mathrm{Z}$ depending on $\mathrm{dX} / \mathrm{d} \phi$ to depending on $\mathrm{Y}$. By visually inspecting variation curves from the December 1989 period for the two pairs DER/TEL and HED/VER we found the change occurred between these two with DER depending more on $\mathrm{dX} / \mathrm{d} \phi$ and HED depending on $\mathrm{Y}$. To the south the changeover is between Carnarvon $\left(24.9^{\circ} \mathrm{S}\right.$ on the west coast) and Geraldton (GER). (The Carnarvon data used were from 12 to 18 May 1990 since that station was not operating in December 1989). Thus visual inspection of the variation curves shows that it is only the small group of stations between Carnarvon and Port Hedland (HED) which exhibit the relation between $\mathrm{Z}$ and $\mathrm{Y}$.

We have also examined the records for this December period from Cooktown (CKT) and Charters Towers (CTA) on the north-east coast. $\mathrm{Z}$ at CKT (not shown in a diagram) is remarkably similar to $\mathrm{Z}$ at Wyndham, the main difference being a slightly larger post-noon maximum. The morning minimum is clearly visible at CKT. Z at CTA is again similar but with the morning minimum slightly less prominent. The variations at CTA and MYB are quite different as is evidenced by their phases in Table 1 . This change in behaviour of $\mathrm{Z}$ between the north-east and the rest of the east coast shows clearly in the phase lag diagrams of Whellams (1996), both at the 12 and $24 \mathrm{~h}$ periods.

On the south coast we would expect $\mathrm{Z}$ to be similar to $\mathrm{X}$, if $\mathrm{Z}$ reacts to the onshore component, which would be northward. Rarely do we find this to be so.

We will look first at Eucla (EUC) on the south coast. In Fig. 7 we can see no correlation between $\mathrm{Z}$ and $\mathrm{Y}$ here. The correlation between $\mathrm{Z}$ and $\mathrm{dX} / \mathrm{d} \phi$ is better. Here we estimate $\mathrm{dX} / \mathrm{d} \phi$ by subtracting Eucla $X$ from Giles (GIL) $X$. All the deviations are now positive in both $\mathrm{Z}$ and $\mathrm{dX} / \mathrm{d} \phi$.

In May X is consistently negative (southward) at Eucla, since the focus is further north during this season, but the $Z$ variation remains positive. The relation of $Z$ to $d X / d \phi$ in May is also quite good.

At Esperance the agreement between $\mathrm{Z}$ and $\mathrm{dX} / \mathrm{d} \phi$ is re-

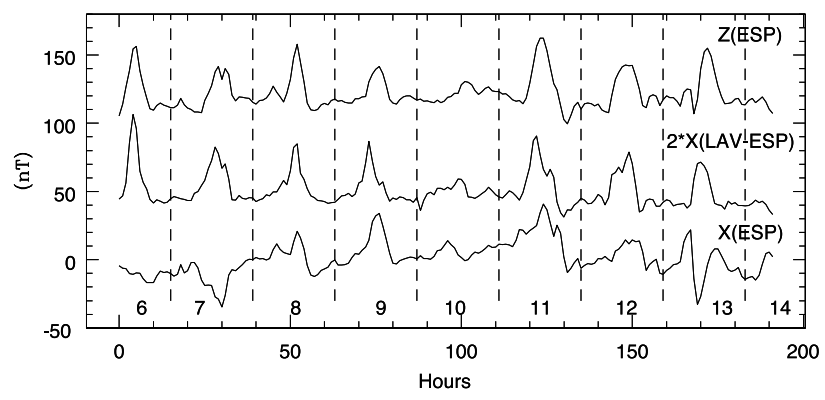

Fig. 8. X and Z variations for 6-13 December 1989 at Esperance (ESP) together with $\mathrm{dX} / \mathrm{d} \phi$ from subtracting $\mathrm{X}$ at ESP from $\mathrm{X}$ at Laverton (LAV).
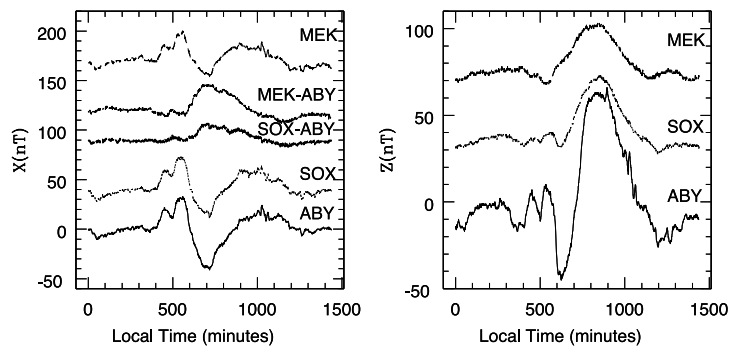

Fig. 9. One minute data for 13 December 1989 of Z (right panel) and $\mathrm{X}$ (left panel) for stations in south-west Australia, together with two estimates of $\mathrm{dX} / \mathrm{d} \phi$ at Albany (ABY) using $\mathrm{X}$ values at MEK and at SOX to subtract from $\mathrm{X}$ values at ABY.

markably good (Fig. 8) and, further east at Port Augusta (PTA) $\mathrm{Z}$ and $\mathrm{dX} / \mathrm{d} \phi$ provide the best correlation. It therefore seems that generally, for periods typical of the daily variation, the coast effect is almost absent to the south of the continent. The situation is different at shorter time periods. In Fig. 9 we show an example of this where one minute values are plotted and the higher frequency variations in $\mathrm{Z}$ at $\mathrm{ABY}$ (periods of about $2 \mathrm{~h}$ ) relate directly to the $\mathrm{X}$ variation at $\mathrm{ABY}$ and not to $\mathrm{dX} / \mathrm{d} \phi$ (as measured by the differences in $\mathrm{X}$ at SOX and $\mathrm{ABY}$ or MEK and $\mathrm{ABY}$ ).

\section{Morning Eastward Current}

As mentioned earlier in connection with Fig. 1, an extra eastwards current system often appears in the morning and this has been discussed in detail by Stening et al. (2005a). Evidence of this current system can also be seen in Fig. 6 where, on 8 and 9 December, both $\mathrm{Z}$ and $\mathrm{dX} / \mathrm{d} \phi$ have predominantly negative deviations. The data tell us that at this morning time the deviation in $\mathrm{X}, \Delta \mathrm{X}$, is increasing towards the pole rather than towards the equator as it normally does. While Stening et al. (2005a) found this current system did not fit well with the $\mathrm{Sq}^{\mathrm{p}}$ system, this present finding suggests that these currents are stronger at higher latitudes and weaken going equatorward. The morning minimum is a persistent feature in Fig. 6, sometimes accompanying a maximum just past noon. This minimum can also be seen in Fig. 2 for stations towards the west side of the continent. One of the sources of day-to-day variability is the time at which the eastward current system is replaced by the whorl of the Sq current system coming in from the east. This will be influenced by the relative strengths of these two current systems, both of which can be clearly seen in Fig. 1 . 


\section{Discussion}

Our concern in this paper is to understand the different forms of the quiet daily variation $\mathrm{Sq}(\mathrm{Z})$ around Australia. We have found two areas on the east and west coasts where $\mathrm{Sq}(\mathrm{Z})$ appears to be somewhat controlled by the onshore component of the horizontal variation, $\mathrm{Y}_{O}$, though the phase agreement is not exact. However this effect appears to be restricted in latitude. Other workers have sought to make inferences about the underlying conductivity structure from such information, but this is a complicated matter as the responses are frequency dependent. Here we are mainly interested in periods associated with $\mathrm{Sq}(\mathrm{Z})$, that is $24 \mathrm{~h}$ and $12 \mathrm{~h}$. In this way we actually came to a different conclusion regarding the variations at Gnangara (GNA) to that of Lilley and Parker (1976). They found the "anomalous" component of $\mathrm{Z}$ at GNA responded to the onshore component $\mathrm{Y}_{O}$. However the response they found was best at the shorter $6 \mathrm{~h}$ and $8 \mathrm{~h}$ periods while at $24 \mathrm{~h}$ they obtained a $90^{\circ}$ phase difference which is confirmed by the results in Table 1. This may explain why our results showed $\mathrm{Z}$ at Gnangara responding more to $\mathrm{dX} / \mathrm{d} \phi$.

Around the rest of the coast $\mathrm{Sq}(\mathrm{Z})$ seemed to reflect the changes in strength of the overhead ionospheric currents more than induction effects. It is important for researchers to know which stations are significantly affected by induction when they are studying the morphology of ionospheric currents.

The "coastal effect" in $\mathrm{Z}$ at periods of $12,24 \mathrm{~h}$ is not so simple that it can just be related to the onshore variation $\mathrm{Y}_{O}$. Often there is a significant phase difference between $\mathrm{Z}_{A}$ and $\mathrm{Y}_{O}$ which cannot be resolved by adjusting the angle $\mathrm{Y}_{O}$ makes with the coastline. The region on the east coast around Newcastle (NEW), where an anomalous $\mathrm{Z}$ was identified, coincides with an ocean depth of more than $6 \mathrm{~km}$ at less than $100 \mathrm{~km}$ from the coast. In comparison ocean depths off the north-east coast and along the south coast are much shallower, often less than $200 \mathrm{~m}$. The situation on the west coast is less clear. For example the $200 \mathrm{~m}$ isobath is about $200 \mathrm{~km}$ from the coast at HED. We might expect that the coast effect would be more prominent in regions where the ocean is deeper near the coast. However we must recognise that the longer period variations are influenced by conductivity structures at greater depth. Only sometimes may these deep conductivity structures coincide with coastlines.

\section{Conclusions}

1. On parts of the west and east coasts of Australia the daily variation of $\mathrm{Z}$ relates mostly to the onshore horizontal component variation, though with some phase difference. On the west coast this effect is restricted to the zone between $20^{\circ} \mathrm{S}$ and $30^{\circ} \mathrm{S}$. On the east coast it occurs between $22^{\circ} \mathrm{S}$ and about $35^{\circ} \mathrm{S}$.

2. Our results from the north coast show little "coast effect" and the $Z$ variation reflects the change in amplitude with latitude of the overhead east-west ionospheric currents, as measured by the latitudinal gradient in $\mathrm{X}, \mathrm{dX} / \mathrm{d} \phi$. This gradient is likely to be larger at a station between the $\mathrm{Sq}$ focus and the equator when the focus is at a lower latitude, and there is some evidence that this is so.

3. On the south coast $\mathrm{Z}$ again mostly follows $\mathrm{dX} / \mathrm{d} \phi$, though amplitudes correspond less well than times of maxima and minima.

4. Derivation of the anomalous coast effect $Z_{A}$ verified these findings. However it seemed that $\mathrm{Z}_{A}$ was not only just related to the horizontal onshore component but an additional phase difference was also required at the longer 12, $24 \mathrm{~h}$ periods considered here.

5. Different behaviours and relations for shorter period variations were demonstrated.

6. On some days a negative excursion in $\mathrm{Z}$ was found in the morning hours, together with a positive $X$. This indicated an eastward ionospheric current with amplitude increasing towards the pole corresponding to the extra morning current system earlier identified by Stening et al. (2005a).

Acknowledgments. We thank Drs. Francois Chamalaun and Dr. Charles Barton for making their AWAGS data available. We also thank Dr. Ted Lilley for helpful suggestions and Dr. Jon Turner for programming in connection with Fig. 1. We have appreciated suggestions made by our reviewers.

\section{References}

Bennett, D. J. and F. E. M. Lilley, An array study of daily magnetic variations in southeast Australia, J. Geomagn. Geoelectr., 25, 39-62, 1973.

Chamalaun, F. H. and C. E. Barton, The large-scale electrical conductivity structure of Australia, J. Geomag. Geoelectr., 45, 1209-1212, 1993a.

Chamalaun, F. H. and C. E. Barton, Electromagnetic Induction in the Australian Crust: Results from the Australian-Wide Array of Geomagnetic Stations, Exploration Geophysics, 24, 179-186, 1993b.

Everett, J. E. and R. D. Hyndman, Geomagnetic variations and electrical conductivity structure in south-western Australia, Phys. Earth Planet. Interiors, 1, 24-34, 1967.

Gough, D. I., M. W. McElhinny, and F. E. M. Lilley, A magnetometer array study in Southern Australia, Geophys. J. R Astr. Soc., 36, 345362, 1974.

Lilley, F. E. M. and R. L. Parker, Magnetic daily variations compared between the east and west coasts of Australia, Geophys. J. R. Astr. Soc., 44, 719-724, 1976.

Matsushita, S., Solar quiet and lunar daily variation fields, in Physics of Geomagnetic Phenomena, edited by S. Matsushita and W. H. Campbell, Academic Press, New York, 1967.

Parkinson, W. D. and F. W. Jones, The geomagnetic coast effect, Rev. Geophys. Space. Phys., 17, 1999-2015, 1979.

Srivastava, B. J., H. Abbas, T. RamaGopal, D. R. K. Rao, and B. M. Pathan, Geomagnetic coast and other effects deduced from the new observatory at Visakhapatnam, India, Geophys. J. Int., 146, 827, 832, 2001.

Stening, R. J. and P. A. Hopgood, Geomagnetic quiet daily variations in the Australian region-information from a new station at Charters Towers (20.1 ${ }^{\circ}$ S), J. Atmos. Terr. Phys., 53, 959-964, 1991.

Stening, R., T. Reztsova, D. Ivers, J. Turner, and D. Winch, Morning quiet-time ionospheric current reversal at mid to high latitudes, Annales Geophysicae, 23, 385-391, 2005a.

Stening, R., T. Reztsova, D. Ivers, J. Turner, and D. Winch, A critique of methods of determining the position of the focus of the Sq current system, J. Geophys. Res., 110, A04305, doi: 10.1029/2004JA010784, 2005b.

Whellams, J. M., Spatial inhomogeneity of geomagnetic fluctuation fields and their influence on high resolution aeromagnetic surveys, $\mathrm{PhD}$ thesis, Flinders University of South Australia, 1996.

R. J. Stening (e-mail: R.Stening@unsw.edu.au) and T. Reztsova 